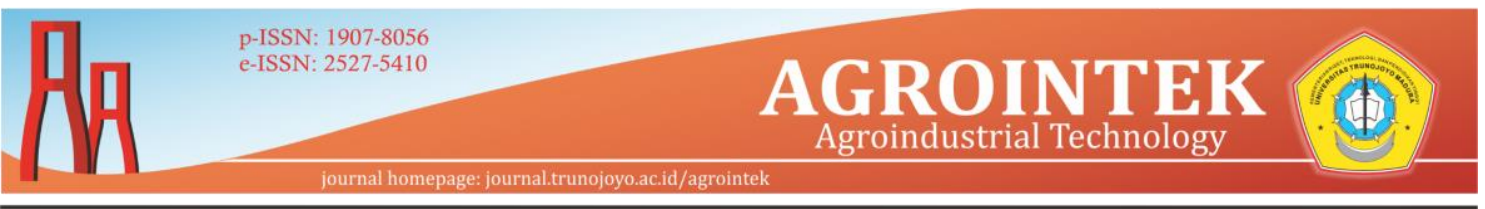

\title{
ANALISIS KUALITAS JAMUR KRISPY BERBASIS KEPUASAN KONSUMEN (STUDI KASUS: IKM BERKAH CINTA TRENGGALEK)
}

\author{
Yuli Wibowo $^{1}$, Bambang Herry Purnomo ${ }^{1}$, Ulfa Nur Aida ${ }^{1 \dagger}$ \\ ${ }^{1}$ Jurusan Teknologi Industri Pertanian, Universitas Jember, Jember
}

Article history
Diterima:
4 Februari 2019
Diperbaiki:
17 Juni 2019
Disetujui:
18 Juni 2019
Keyword
Crispy Mushrooms,
Customer
Satisfaction,
Quality

\begin{abstract}
Small-Medium Enterprise (SME) Berkah Cinta Trenggalek (BCT) is a that produces snacks in the form of crispy mushrooms with the brand name of the "Jamur Mantan", with the main sales in the Kediri regency. Was established in 2017, so this SME can classified as a new home industries and have faced some business competitors with similar snacks produced. Therefore, it is important to created customer satisfaction by improved quality of product. The purposed of this study is to know the level consumer satisfaction crispy mushrooms, the indicators of each product quality attribute that are considered important by consumers for the quality improvement processed, the results of the analysis of technical specifications that have high relevancy in the effort to formulate recommendation for improving the quality of the crispy mushrooms, formulate recommendation that can be used for the processed of improving the quality of the crispy mushroom SME BCT. The data analysis method used to measured the level customer satisfaction is the Customer Satisfaction Indes (CSI), Importance Performance Analysis (IPA) to determined the performance level of each atribute, and Matrix Diagram to find out the relationship between technical speafications of making crispy mushrooms and low performance quality indicators. The results of this study was indicated that level of customer satisfaction with crispy mushrooms from the CSI method as 79,73\%. The analysis used IPA obtained 5 quality atribute indicators that performed low with hight customer expectation. So, this 5 indicators needed further analysis used the Matrix Diagram, the results obtained showed 3 that the formulate recomendations that can be used for the quality improvement. There are improving design product by re-design products, lre-design for the right compositions to produced flavor that tasty and consistent, and regulates the use of cooking oil.
\end{abstract}

(C) hak cipta dilindungi undang-undang

\footnotetext{
$\dagger$ Penulis korespondensi

Email: ulfa.noeraida@gmail.com

DOI: http://dx.doi.org/10.21107/agrointek.v13i2.4890
} 


\section{PENDAHULUAN}

Kemajuan di bidang perekonomian saat ini telah mendorong pertumbuhan di berbagai sektor usaha, salah satunya pada sektor usaha di bidang produksi yang ditandai dengan munculnya industri baru. Kondisi ini akan akan menyebabkan tingkat persaingan antar industri akan semakin ketat. Salah satu aspek untuk memenangkan persaingan pasar adalah menciptakan kepuasan pada konsumen dengan cara peningkatan kualitas produk.

Kepuasan konsumen menurut Umar (2002) adalah tingkat perasaan seseorang setelah membandingkan kinerja atau hasil yang dirasakan dengan harapannya, kemudian konsumen menentukan rasa puas atau tidak puas terhadap suatu produk ataupun jasa tersebut. Analisa kepuasan konsumen dari setiap indikator kualitas produk, akan didapatkan nilai dari setiap indikator atribut kualitas yang memiliki hasil penilaian tersendiri dari konsumen. Hasil analisis atribut kualitas yang kurang baik, harus diperhatikan dengan cara proses peningkatan kualitas.

IKM Berkah Cinta Trenggalek merupakan industri menengah yang memproduksi makanan ringan berupa jamur krispy dengan nama brand Jamur Mantan, dengan penjualan utama di daerah Kediri. IKM ini berdiri pada tahun 2017. Pihak perusahaan menyadari akan pentingnya peningkatan kualitas produk agar mampu memberikan kepuasan untuk semua pelanggannya sehingga dapat memenangkan persaingan usaha. Oleh karena itu, perlu dilakukan analisa pengukuran tingkat kepuasan konsumen terhadap produk dengan melakukan penilaian atribut mutu yang telah ditetapkan. Tujuannya untuk mengetahui besaran tingkat kepuasan konsumen atas kinerja suatu produk. Hasil analisa tersebut nantinya dapat digunakan untuk merumuskan kebijakan yang tepat dalam peningkatkan kualitas produk diperusahaan.

Berdasarkan latar belakang tersebut, maka diperoleh tujuan penelitian yaitu mengetahui tingkat kepuasan konsumen Jamur Krispy IKM BCT, mengetahui indikator dari setiap atribut kualitas produk yang dianggap penting oleh konsumen untuk proses peningkatan kualitas, mengetahui hasil analisis spesifikasi teknis yang memiliki keterkaitan tinggi dalam upaya perumusan kebijakan peningkatan kualitas Jamur Krispy IKM BCT, merumuskan kebijakan yang dapat digunakan untuk proses peningkatan kualitas Jamur Krispy IKM BCT. Adapun manfaat yang diperoleh dari penelitian ini yaitu sebagai bahan referensi untuk membantu memberikan masukan dan pertimbangan terhadap proses peningkatan kualitas produk yang sesuai dengan keinginan konsumen, memberikan gambaran bagi perusahaan dalam menentukan kebijakan yang tepat dan terarah untuk mengelola produk secara efektif dan efisien.

\section{METODE}

\section{Tempat dan Waktu penelitian}

Penelitian ini dilaksanakan di IKM BTC (Berkah Cinta Trenggalek), yang berlokasi di Jalan Armyn Pane Kelurahan Sumbergedong, Kecamatan Trenggalek, Kabupaten Trenggalek. dan waktu pengambilan data penelitian dilakukan pada bulan September - Oktober 2018 .

\section{Alat dan Bahan}

Alat dan bahan yang digunakan dalam penelitian adalah software SPSS 16.0 dan quisioner.

\section{Analisis Data}

Pada penelitian ini dilakukan tahapan yaitu dengan tahapan pembuatan quisioner, analisa validasi dan reliabilitas quisioner, metode Customer Satisfaction Index (CSI), metode Importance Performance Analysis 
(IPA), yang dilanjutkan dengan analisa atribut kualitas yang perlu ditingkatkan menggunakan Matrix Diagram. Sehingga tahapan yang digunakan dalam penelitian ini sebagai berikut:

\section{Pembuatan quisioner}

Quisioner merupakan daftar pertanyaan yang akan digunakan oleh peneliti untuk memperoleh data dari sumbernya secara langsung melalui proses komunikasi atau dengan mengajukan pertanyaan. Penyusunan kuisioner dilakukan untuk memilih pertanyaanpertanyaan yang akan disajikan dalam quisioner agar pertanyaan yang diajukan kepada responden mudah dimengerti dan hasil yang didapatkan sesuai dengan kebutuhan yang diteliti.

2. Uji Validitas dan Reliabilitas

Uji validitas digunakan untuk mengukur ketepatan dan kesahihan suatu instrumen penelitian. Dengan tingkat kepercayaan: $\mathrm{A}=0.05$; $\mathrm{df}=\mathrm{n}-2=30-2$ $=38 ; \mathrm{r}$ tabel $=0.361$, dikatakan valid apabila $r$ hitung $\geq r$ tabel dan sebaliknya.

Uji realibitas digunakan untuk melihat ketepatan quisioner sebagai alat ukur yang apabila diberikan secara berulang-ulang kepada responden yang sama akan menghasilkan data yang serupa (Simamora, 2002). Dengan nilai Cronbach's Alpha sebesar 0,60, dinyatakan reliabel apabila nilai Cronbach's Alpha $\geq 0,60$ dan sebaliknya.

\section{Customer Satisfaction Index (CSI)}

CSI digunakan untuk menentukan tingkat kepuasan konsumen secara menyeluruh dengan pendekatan yang mempertimbangkan tingkat kepentingan dari atribut-atribut yang diukur. Menurut Stratford (2004) metode pengukuran CSI meliputi tahap-tahap sebagai berikut :

a. Mengukur tingkat kepentingan dan tingkat kepuasan dari setiap atribut yang mempengaruhi kepuasan konsumen menggunakan skala likert hasil quisioner yang telah dibuat dan disebarkan untuk konsumen jamur krispy.

b. Menentukan Mean Importance Score (MIS-i) dan Mean Satisfication Score (MSS). Nilai ini didapat dari nilai ratarata tingkat kepentingan dan rata-rata tingkat kinerja tiap atribut.

$M S S=\frac{\sum_{i=1}^{n} Y_{i}}{n} ; \quad M I S=\frac{\sum_{i=1}^{n} X_{i}}{n}$

Keterangan:

$\mathrm{Xi}$ : Nilai kinerja atribut ke-i

Yi : Nilai kepentingan atribut ke-i

$\mathrm{n}$ : Jumlah responden

c. Weight Factor (WF), adalah fungsi dari Mean Importance Score atau nilai dari rata-rata tingkat kepentingan (MIS-i) masing-masing atribut yang dinyatakan dalam bentuk persen terhadap total Mean Importance Score untuk seluruh atribut yang diuji.

$$
W F=\frac{M I S-i}{\text { Total MIS }-i} \times 100 \%
$$

d. Weighted Score (WS), adalah fungsi dari Mean Satisfication Score (MSS) dikali dengan Weighting Factor (WF). Mean Satisfication Score atau nilai rata tingkat kepuasan diperoleh dari nilai rata-rata tingkat performance atau nilai rata-rata tingkat kinerja dari suatu atribut.

$$
W S=M S S x W F
$$

e. Weight Average Total (WAT), adalah fungsi dari total Weighted Score (WS) atribut ke-1 $(\alpha 1)$ hingga atribut ke-n (an).

$W A T=W S \alpha 1+W S \alpha 2+\ldots+W S \alpha n$

f. Customer Satisfaction Index, yaitu fungsi dari nilai Weight Average (WA) dibagi dengan Highest Scale (HS) atau yang dinyatakan dalam 
bentuk persen. HS adalah skala maksimum yang digunakan (Stratfod, 2004). Skala maksimum diperoleh dari ukuran skala Likert yang digunakan dalam pembobotan tingkat kepentingan dan kinerja. Maka dalam penelitian ini skala maksimum yang digunakan yaitu lima.

$$
C S I=\frac{\sum W S}{H S} \times 100 \%
$$

Rentang skala pada Indeks Kepuasan Konsumen digunakan untuk menunjukkan tingkat kepuasan konsumen terhadap produk dan jasa. Menurut Aritonang (2005), penentuan angka indeks pada kriteria nilai CSI menggunakan skala numerik dengan rumus sebagai berikut:

$$
R s=\frac{(m-n)}{b}
$$

Sehingga dihasilkan tabel CSI sebagai berikut:

Tabel 1 Nilai Customer Satisfaction Index

\begin{tabular}{cl}
\hline Angka Indeks & Interpretasi \\
\hline $0 \%-20 \%$ & Sangat tidak puas \\
$21 \%-40 \%$ & Tidak puas \\
$41 \%-60 \%$ & Cukup puas \\
$61 \%-80 \%$ & Puas \\
$81 \%-100 \%$ & Sangat puas \\
\hline
\end{tabular}

4. Importance Performance Analysis (IPA)

IPA merupakan suatu teknik yang digunakan untuk mengukur atribut-atribut dari tingkat kepentingan dengan tingkat kinerja yang diharapkan konsumen. Hasil analisa IPA dinotasikan kedalam diagram kartesius. Gambar 1 menunjukkan diagram kartesius IPA.

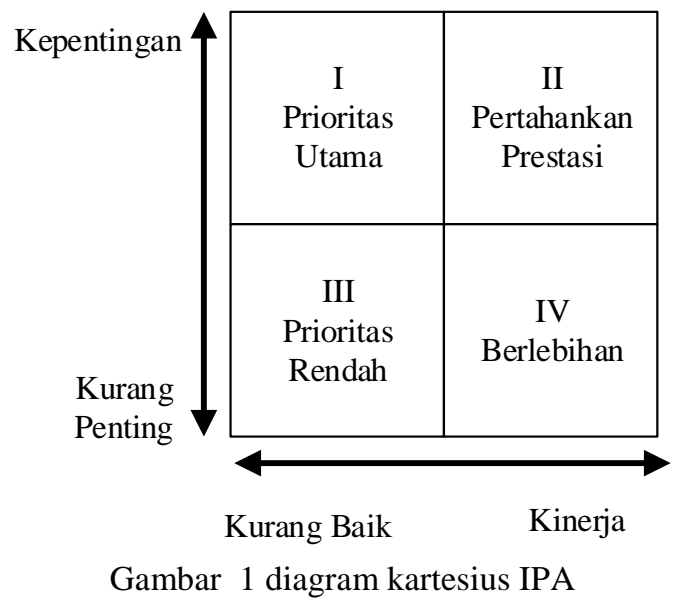

Matriks IPA terdiri dari empat kuadran yaitu kuadran pertama terletak di sebelah kiri atas, kuadran kedua di sebelah atas, kuadran ketiga di sebelah kiri bawah, dan kuadran empat di sebelah kanan bawah.

\section{Kuadran I (Prioritas Utama)}

Kuadran ini memuat atribut-atribut yang dianggap penting oleh konsumen namun pada kenyataannya kinerja dari atribut ini belum sesuai dengan yang diharapkan (Rangkuti, 2006). Artinya tingkat kepuasan yang diperoleh konsumen masih sangat rendah dan perlu melakukan perbaikan terus menerus.

\section{Kuadran II (Pertahankan Prestasi)}

Kuadran ini memuat atribut-atribut yang dianggap penting oleh konsumen dan pihak perusahaan telah melaksanakannya sesuai dengan yang diharapkan oleh konsumen (Rangkuti, 2006). Hal ini menuntut perusahaan untuk dapat mempertahankan posisinya.

\section{Kuadran III (Prioritas Rendah)}

Kuadran ini memuat atribut-atribut yang dianggap kurang penting pengaruhnya oleh konsumen, dan pada kenyataannya kinerjanya juga tidak terlalu istimewa (Rangkuti, 2006). Perbaikan atau peningkatan kinerja atribut-atribut yang terdapat dalam kuadran ini dapat 
dipertimbangkan kembali karena pengaruhnya kecil terhadap konsumen.

\section{Kuadran IV (Berlebihan)}

Kuadran ini memuat atribut-atribut yang dianggap kurang penting pengaruhnya bagi konsumen, akan tetapi pelaksanaannya telah dijalankan dengan sangat baik oleh pihak perusahaan (Rangkuti, 2006). Kinerja atribut-atribut yang termasuk dalam kuadran ini dapat dikurangi agar dapat menghemat biaya.

\section{Matrix Diagram}

Matrix diagram adalah salah satu alat perencanaan manajemen dari tujuh alat manajemen dan perencanaan atau yang disebut dengan 7 New Quality Tools (Shuai dan Kun, 2013). Berfungsi untuk mendapatkan informasi tentang sifat dan kekuatan dari permasalahan yang berkaitan untuk mendapatkan ide-ide untuk memecahkan masalah (Diammardi, 2011). Salah satu bentuk matrix diagram yaitu LMatrix Diagram.

Diagram alir penelitian dapat dinyatakan dalam Gambar 2 sebagai berikut.

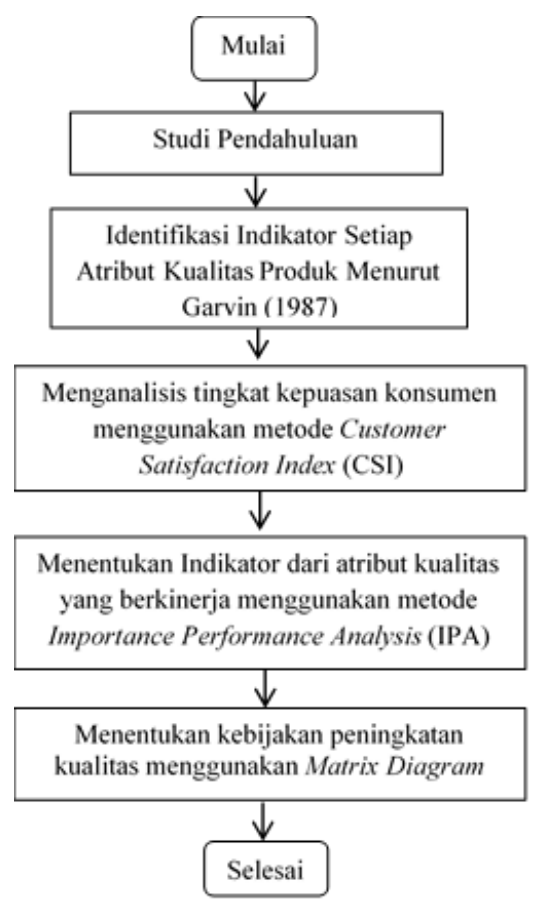

Gambar 2 diagram alir penelitian

\section{HASIL DAN PEMBAHASAN Uji Quisioner}

Hasil uji validitas pada penelitian menunjukkan bahwa variabel-variabel tersebut telah diuji validitas terhadap 30 responden. Hasil pengujian menunjukkan bahwa semua atribut kualitas valid, karena memiliki nilai $r$ hitung yang lebih besar dari pada $r$ tabel $(0,361)$. Oleh karena itu, kuesioner dapat dijadikan sebagai tolak ukur dalam penelitian ini.

Uji reliabilitas dilakukan menggunakan SPSS 16.0 dengan metode Cronbach's Alpha yaitu dapat dikatakan reliabel apabila diperoleh nilai Cronbach's Alpha lebih besar dari pada 0,60. Hasil pengujian reliabilas pada penelitian ini menunjukkan bahwa quisioner reliabel, karena memiliki nilai Cronbach's Alpha lebih dari 0,6.

\section{Analisis Tingkat Kepuasan Pelanggan}

Nilai CSI yaitu sebesar $79,73 \%$. Nilai ini berada pada rentang $61 \%-80 \%$ menurut hasil perhitungan menggunakan persamaan perhitungan penentuan indeks CSI Aritonang (2005), dengan demikian indeks kepuasan konsumen berdasarkan atribut kualitas kinerja produk Jamur Mantan produksi IKM Berkah Cinta Trenggalek termasuk dalam kriteria puas. Dari hasil perhitungan tersebut, sebaiknya IKM BCT terus mengendalikan kualitasnya dan bahkan meningkatkan kualitasnya karena masih terdapat $20,27 \%$ dari kepuasan konsumen yang belum terpenuhi oleh pihak IKM. BCT. Selain itu, dengan nilai CSI yang mendekati angka 100 itu akan lebih baik dan konsumen akan merasa sangat puas terhadap produk yang ditawarkan. Menurut Ariani (2012) nilai CSI dapat ditingkatkan dengan melakukan perbaikan kinerja pada tiap indikator atribut kualitas hasil dari analisis menggunakan Importance Performance Analysis (IPA). 
Analisis Indikator Atribut Kualitas yang Berkinerja

1. Tingkat Kesesuaian

Pengolahan data pada tingkat kesesuaian ini dilakukan bertujuan untuk melihat atribut-atribut yang perlu untuk dilakukannya perbaikan (Action) dan juga untuk melihat atribut-atribut yang perlu dipertahankan oleh pihak perusahaan (Hold) yang dinilai berdasarkan perbandingan nilai tingkat kesesuaian dengan nilai skor pengambilan keputusan. Hasil perhitungan yang telah dilakukan sebelumnya terdapat beberapa atribut yang harus mendapat perhatian lebih, atau perlu dilakukannya perbaikan karena atribut tersebut masih belum dapat memuaskan pelanggan, yaitu sebanyak 10 atribut. Atribut yang perlu mendapatkan perhatian untuk dipertahankan kualitasnya oleh pihak IKM sebanyak 18 atribut.

\section{Diagram Kartesius}

Diagram kartesius digunakan untuk menempatkan posisi dari tiap atribut dimensi kualitas produk dari tingkat kinerja dan kepentingan produk Jamur Krispy IKM Berkah Cinta Trenggalek dapat menggunakan grafik IPA atau diagram kartesius. Diagram kartesius bertujuan untuk menggambarkan posisi tingkat kepentingan dan tingkat kepuasan dari tiap atribut dimensi kualitas produk. Pada diagram ini disajikan secara jelas mengenai atribut dimensi kualitas produk Jamur Krispy berdasarkan tingkat kepentingan yang diharapkan oleh konsumen dan tingkat kinerja kepuasan konsumen produk Jamur Krispy. Berikut diagram kartesius jamur krispy.

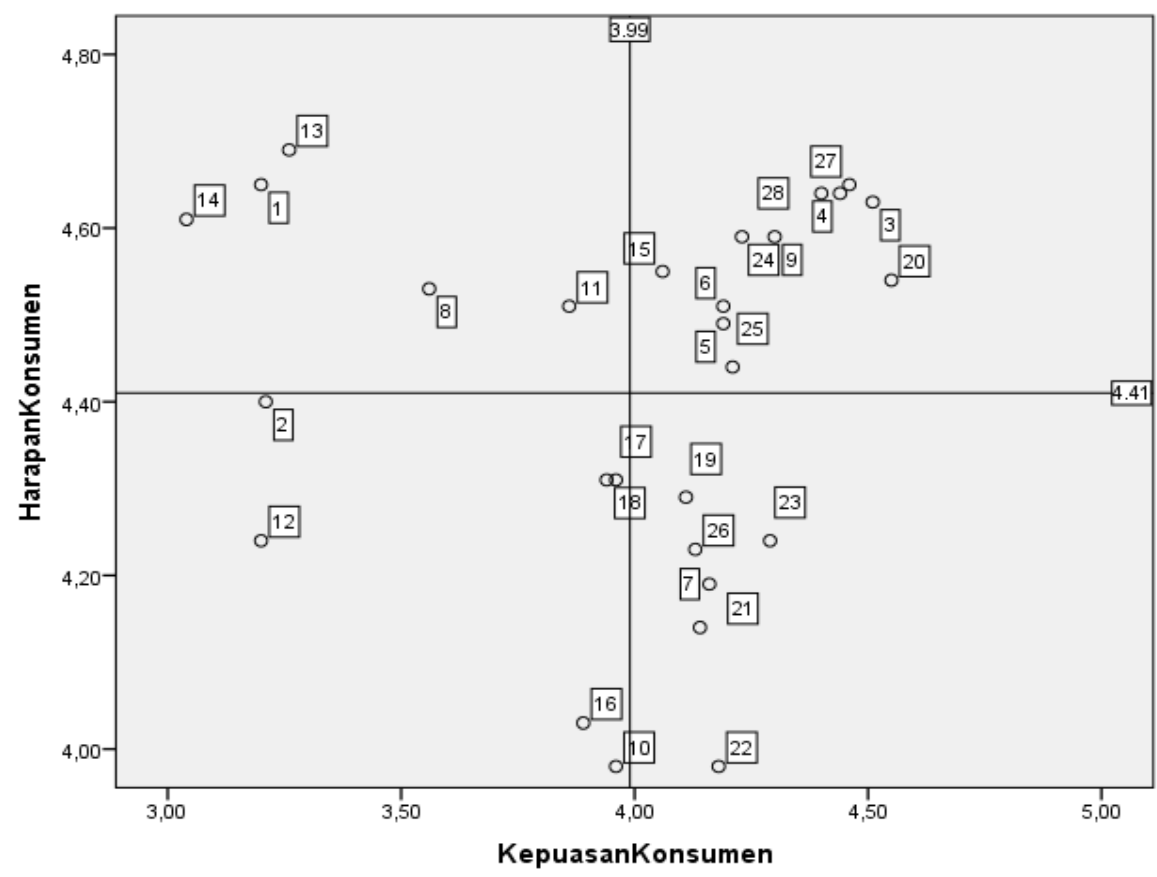

Gambar 3 diagram kartesius jamur krispy

\section{a. Kuadran I (Prioritas Utama)}

Kuadran I pada diagram kartesius menunjukkan bahwa suatu atribut kualitas produk yang dianggap sangat penting oleh konsumen, namun kinerja dari atribut tersebut masih dinilai rendah atau belum maksimal oleh konsumen. Atribut yang termasuk dalam kuadran ini harus dijadikan prioritas utama untuk dilakukan perbaikan oleh pihak IKM agar kepuasan konsumen menjadi meningkat. Berdasarkan pemetaan hasil penelitian terdapat 5 indikator atribut kualitas yang 
berada pada kuadran I yaitu rasa produk enak, tambahan nilai gizi, kemasan tidak mudah penyok, rasa produk konsisten, dan harga produk sesuai dengan kualitas yang didapatkan.

Hasil penelitian pada kuadran I, menunjukkan indikator atribut kualitas yang menjadi prioritas utama bagi IKM Berkah Cinta Trenggalek untuk dilakukan perbaikan kualitas agar konsumen merasa puas terhadap produk yang ditawarkan. Hal ini sesuai dengan pendapat Raharjani (2005) yang mengatakan bahwa kepuasan konsumen dapat dicapai apabila konsumen merasa kebutuhan akan suatu kebutuhannya terpenuhi dan mendapatkan pelayanan yang baik.

\section{b. Kuadran II (Pertahankan Prestasi)}

Kuadran II pada diagram kartesius menunjukkan bahwa atribut-atribut kualitas produk yang memiliki nilai tinggi dan sesuai dengan harapan konsumen, baik dalam nilai tingkat kepentingan maupun tingkat kinerjanya. Atribut yang termasuk dalam kuadran ini perlu dipertahankan kinerja kualitas produknya oleh pihak IKM karena atribut tersebut berada pada posisi di atas rata-rata dan sudah sesuai dengan harapan konsumen. Berdasarkan pemetaan hasil penelitian terdapat 11 indikator atribut kualitas yang berada pada kuadran II yaitu kerenyahan produk, penampakan kebersihan produk, kepraktisan kemasan, label informatif, jaminan sehat dan higiene produk, produk tahan lama, desain kemasan yang baik, warna tulisan menarik, bahan kemasan yang baik dan aman, citra produk positif di masyarakat, produk bersertifikat halal, produk memiliki ijin yang baik .

c. Kuadran III (Prioritas Rendah)

Kuadran III pada diagram kartesius menunjukkan bahwa atribut-atribut kualitas produk dianggap kurang penting oleh konsumen dan kinerja yang diberikan juga masih rendah atau biasa saja. Atribut yang berada pada kuadran ini memiliki tingkat prioritas perbaikan yang rendah. Berdasarkan pemetaan hasil penelitian terdapat 6 indikator atribut kualitas yang berada pada kuadran III yaitu aroma produk, fungsi snack sebagai camilan ataupun oleh-oleh, bentuk potongan produk, penyimpanan produk, kecepatan pelayanan apabila terjadi komplain, serta kemudahan memperoleh produk.

\section{d. Kuadran IV (Berlebihan)}

Kuadran IV pada diagram kartesius menunjukkan bahwa atribut-atribut kualitas produk yang memiliki tingkat kepentingan dianggap rendah oleh konsumen namun dari kenyataannya dijalankan dengan sangat baik oleh perusahaan, sehingga atribut yang berada pada kuadran ini dianggap berlebihan dan perlu tindakan penurunan kualitas. Berdasarkan pemetaan hasil penelitian terdapat 6 indikator atribut kualitas yang berada pada kuadran IV yaitu banyak varian rasa, pelayanan saat membeli produk sesuai dengan harapan, warna kemasan menarik, warna tulisan menarik, bentuk kemasan menarik, kepopuleran merk. 


\begin{tabular}{|c|c|c|c|c|c|c|}
\hline Spesifikasi Telnis & $\begin{array}{c}\text { Rasa } \\
\text { produk }\end{array}$ & $\begin{array}{l}\text { Tambaban } \\
\text { ailai gixi }\end{array}$ & $\begin{array}{l}\text { Kemasan } \\
\text { tidak } \\
\text { mudah } \\
\text { penyok }\end{array}$ & $\underset{\substack{\text { produk } \\
\text { kosisten }}}{\text { Rosis }}$ & Total & Rasekine \\
\hline Desain produk & $\square$ & $\square$ & $\square$ & $\square$ & 36 & 1 \\
\hline Penyiapan baban baku & $\triangle$ & 0 & $\triangle$ & $\Delta$ & 10 & 5 \\
\hline Sortasi das Pemotonean Jamar & 0 & & & 0 & 2 & 11 \\
\hline Pencucian & $\triangle$ & & & $\Delta$ & 6 & $?$ \\
\hline Pencamperan tepung basah & $\Delta$ & 0 & & $\Delta$ & 7 & 6 \\
\hline Fencampuran tepung Lering & $\square$ & 0 & & $\triangle$ & 13 & 4 \\
\hline Pengzorengan & $\square$ & & & $\square$ & 18 & 3 \\
\hline Peairisas deagan spinner & $\triangle$ & & & O & 4 & 8 \\
\hline Femberias rasa & & 0 & & $\square$ & 19 & 2 \\
\hline Proses sealing & & & $\triangle$ & & 3 & 10 \\
\hline Distribasi produk & $\bigcirc$ & & $\Delta$ & & 4 & 8 \\
\hline
\end{tabular}

Gambar 4 matriks diagram jamur krispy

Keterangan:
$\square: 9$ (sangat berkaitan)
$\circ: 1$ (cukup berkaitan)
$\Delta: 3$ (berkaitan)
: 0 (tidak berkaitan)

\section{Analisis Keterkaitan Spesifikasi Teknis dengan Indikator Kualitas}

Matrix diagram ini bertujuan untuk menentukan hubungan atau korelasi antara masing-masing item dalam dua kumpulan berbagai faktor dan karakteristik. Bentuk korelasinya digambarkan dengan sebuah simbol agar lebih mudah untuk dimengerti. Berikut ini disajikan matrix diagram pada Gambar 4 dari atribut kualitas produk Jamur Krispy IKM Berkah Cinta Trenggalek dengan mengidentifikasi faktor penyebab kepuasan konsumen rendah pada beberapa atribut kualitas produk untuk dapat menarik kebijakan yang dapat digunakan untuk proses peningkatan kualitas. Matrix diagram tersebut, diketahui bahwa yang memiliki hubungan keterkaitan sesuai dengan Kriteria dalam Tabel 2 adalah desain produk, maka spesifikasi teknis inilah yang mempunyai peranan terbesar dalam perbaikan kualitas produk.
Tabel 2 kriteria nilai keterkaitan

\begin{tabular}{cl}
\hline Angka Indeks & Interpretasi \\
\hline$<9$ & Tidak Berkaitan \\
$\mathbf{9 - 1 7}$ & Kurang Berkaitan \\
$\mathbf{1 8 - 2 6}$ & Berkaitan \\
$>\mathbf{2 6}$ & Sangat Berkaitan \\
\hline
\end{tabular}

\section{Rekomendasi Kebijakan Peningkatan Kualitas Jamur Krispy}

Hasil analisis spesifikasi teknis yang memiliki keterkaitan tertinggi dalam upaya peningkatan kualitas, dapat diketahui bahwa spesifikasi teknis yang dapat digunakan dalam perumusan kebijakan peningkatan kualitas Jamur Krispy oleh IKM Berkah Cinta Trenggalek, yaitu:

a. Memperbaiki desain produk dengan melakukan perancangan ulang produk agar mampu memenuhi tujuan yang telah ditetapkan oleh perusahaan yaitu dengan merancang komposisi yang tepat dan cocok untuk produk jamur krispy sesuai 
dengan keinginan konsumen, memperbaiki proses produksi yang dapat merusak kandungan gizi produk, mengganti bahan kemasan dengan alumunium foil, dan membuat takaran yang jelas dalam penambahan bubuk perisa.

b. Merancang ulang ataupun mencari komposisi yang tepat untuk dapat menghasilkan rasa yang enak dan konsisten, serta menganti perisa bubuk yang tidak ada kandungan gizi dengan ekstrak perisa alami yang memiliki kandungan gizi.

c. Pengaturan tekanan yang tetap stabil pada saat proses penggorengan, serta mengatur pemakaian minyak goreng.

\section{KESIMPULAN}

Berdasarkan hasil penelitian yang telah dilakukan, maka diperoleh kesimpulan yaitu nilai kepuasan konsumen produk Jamur Krispy IKM Berkah Cinta Trenggalek sebesar 79,73\% dan termasuk dalam kriteria puas, dengan indikator atribut kualitas produk yang menempati kuadran I dalam diagram kartesius dan menjadi prioritas utama yang harus dilakukan perbaikan peningkatan kualitas terdapat 5 indikator atribut yaitu rasa produk, tambahan nilai gizi, kemasan tidak mudah penyok, rasa produk konsisten, dan harga produk sesuai dengan kualitas yang didapatkan. Berdasarkan analisis spesifikasi teknis yang memiliki keterkaitan tertinggi dalam upaya perbaikan peningkatan kualitas yaitu desain produk, proses pemberian rasa, serta proses penggorengan. Rekomendasi kebijakan yang dapat digunakan untuk proses peningkatan kualitas produk Jamur Krispy adalah memperbaiki desain produk dengan merancang ulang produk untuk menghindari produk degradasi dan mati, merancang ulang komposisi yang tepat untuk menghasilkan rasa yang enak dan konsisten, mengatur tekanan yang tetap stabil pada saat proses penggorengan dan mengatur pemakaian minyak goreng.

\section{DAFTAR PUSTAKA}

Aldisky R, B. H. Purnomo, dan A. Nafi'. 2018. Tingkat Penerimaan Konsumen Sosis Koro Pedang di Kabupaten Jember. Jurnal Agrointek.

Ariani M, Taslim, Fitriani A. 2012. Analisis Preferensi, Kepuasan, dan Loyalitas Konsumen terhadap Hidangan Steak di Waroeng Steak and Shake Cabang Jatinangor, Kabupaten Sumedang. Jurnal Universitas Pajajaran.

Aritonang, L. 2005. Kepuasan Pelanggan. Jakarta: PT. Gramedia Pustaka Utama.

Dianmardi. 2011. New 7 Tools of Quality. http://blog.trisakti.ac.id/dianmardi/fe ed. [diakses tanggal 10 September 2018].

Raharjani, J., 2005. Analisa Faktor-falktor yang Mempengaruhi Keputusan Pemilihan Pasar Swalayan Sebagai Tempat Berbelanja (Studi Kasus pada Pasar Swalayan di Kawasan Seputar Simpang Lima Semarang). Jurnal Studi Manajemen dan Organisasi 2(1).

Shuai, Z. dan W. Kun. 2013. News 7 QC Tools,http://www.math.mun.ca/ var iyath/New7QCTools.pdf. [diakses 24 Agustus 2018].

Simamora, Bilson. 2002. Panduan Riset Perilaku Konsumen. Jakarta: PT. Gramedia Pustaka Utama

Stratford. 2004. District Council Customer Satisfaction Index. httpllwww.stratford.gov.uklcouncil805.cfm.htm. [diakses tanggal 14 Agustus 2018].

Umar, H. 2002. Riset Pemasaran dan Perilaku Konsumen. Jakarta: PT Gramedia Pustaka Utama. 